\title{
Open Locast: How MIT's evolving media platform is being used to improve connections between people and their social, cultural, and physical spaces
}

\author{
Don Mclntyre \\ Institute for Design Innovation \\ Glasgow School of Art \\ Glasgow, Scotland
}

\section{KEYNOTE ABSTRACT}

Open Locast Universities is a partnership between the MIT Mobile Experience Laboratory and a talented, international pool of universities, the aim of which is to explore new ways of utilizing Open Locast, an interactive media platform developed by the MIT Mobile Experience Laboratory, in the urban environment. The goal is to not only to encourage civic engagement, but also to generate new forms of storytelling and civic media. Each university team developed its own independent project using the Open Locast platform.

Locast was born out of a desire by the MIT Mobile Experience Lab to better understand how evolving media technologies could be used to improve connections between people and their social, cultural, and physical spaces. The Open Locast Project itself is a collection of software packages and applications developed with this broad goal in mind.

The platform is designed to enable the rapid prototyping and quick deployment of location-based media prototypes. It is an open-source project composed of two primary components, a Web application and an Android application that act in unison to provide a platform that can be tailored to fit various user experiences.

Consistent across all the diverse range of participants, which included Parsons School of
Design in New York, The Catholic University of Milan and the Pontifical Catholic University of Chile was an understanding of how the needs of the local community as well as the end user were critical in shaping system requirements.

The Glasgow School of Art Masters students involved in the project were divided into two groups, both working in the Highlands of Scotland with rural communities. The first group focused on tourism and the other on health and wellbeing.

The teams were encouraged to adopt a user centric approach to the project, first identifying users and their needs, then developing a service map that was used as a basis from which to determine how Locast functionality might best be utilised.

Coming together at a Symposium at MIT in February 2013, it was clear that despite geographical diversity and variety of approaches adopted by the groups involved, there were parallels in terms of findings and insight.

Don Mclntyre, Programme Director at the Institute for Design Innovation at Glasgow School of Art, will share the techniques and methods used across the range of participating Universities and present findings, conclusions and plans for the future of Locast collaboration. 